\title{
ESCOLHA DO ESTABELECIMENTO DE ENSINO E PERFIS FAMILIARES: UMA FACETA A MAIS DAS DESIGUALDADES ESCOLARES
}

\author{
TANia de Freitas ResendE* \\ Cláudio Marques M. Nogueira** \\ MARIA Alice NogUEIRA ${ }^{* * *}$
}

\begin{abstract}
RESUMO: Utilizando resultados de uma pesquisa desenvolvida com 299 famílias de Belo Horizonte, de camadas populares e de frações inferiores das camadas médias, com filhos matriculados em diferentes tipos de escolas de ensino fundamental, este artigo busca contribuir com os estudos sociológicos sobre a escolha do estabelecimento de ensino. Confirma, com relação aos grupos sociais investigados, a existência de uma associação entre perfil das famílias e tipo de escola escolhido pelos pais e, assim, corrobora a ideia de um "quase-mercado" educativo, no qual se relacionam ofertas educacionais e demandas familiares diferenciadas, reforçando a importância da temática na discussão das desigualdades de escolarização.
\end{abstract}

Palavras-chave: Escolas. Famílias. Escolha. Educação. Quase-mercado.

\section{"SCHOOL CHOICE" AND FAMILY PROFILES:}

ANOTHER FACET OF SCHOOL INEQUALITIES

\begin{abstract}
This paper draws on the results of a research involving 299 low and low-middle class families, whose children were enrolled in different elementary and middle schools in Belo Horizonte. As for the social groups investigated, it confirms the relation between family profiles and the kind of school chosen by parents. It thus supports the idea of a "quasi-market" education on which educational offer and family demands are connected, reinforcing the subject's significance in the discussion about schooling inequalities.
\end{abstract}

Key words: Schools. Families. Choice. Education. Quasi-market.

\footnotetext{
* Doutora em Educação e professora adjunta do Departamento de Ciências Aplicadas à Educação, Faculdade de Educação da Universidade Federal de Minas Gerais (UfMG). E-mail: taniaresbr@gmail.com

* Doutor em Educação e professor adjunto do Departamento de Ciências Aplicadas à Educação, Faculdade de Educação da UfMG. E-mail: cmmn@uol.com.br

*** Doutora em Educação e professora titular do Departamento de Ciências Aplicadas à Educação, Faculdade de Educação da UfMG. E-mail: malicen@terra.com.br
} 


\title{
Choix de l'ÉTABlissement et PROFIls FAMILIAUX: UNE FACETTE DE PLUS DES INÉGALITÉS SCOLAIRES
}

\begin{abstract}
RÉSUMÉ: A partir des résultats d'une recherche développée auprès de 299 familles de classes inférieure et moyenne-inférieure ayant des enfants inscrits dans différents types d'écoles de l'enseignement primaire et du collège à Belo Horizonte, cet article recherche à contribuer aux études sociologiques sur le choix de l'établissement. Pour ce qui est des groupes sociaux étudiés, elle confirme l'existence d'une association entre le profil des familles et le type d'école choisi par les parents et, donc, elle corrobore l'idée d'un "quasi-marché» éducatif où sont en relation les offres éducationnelles et les demandes familiales différenciées, renforçant ainsi l'importance de ce thème dans la discussion des inégalités de scolarisation.
\end{abstract}

Mots-clés: Écoles. Familles. Choix. Éducation. Quasi-marché.

\section{Escolha do estabelecimento de ensino pelas famílias: sobrevoo teórico}

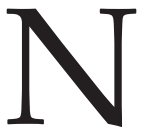

os últimos trinta anos, a Sociologia da Educação tem progressivamente reconhecido a importância de tomar como objeto de estudo a ação parental de escolha do estabelecimento de ensino por famílias de diferentes meios sociais. Partindo, nos anos de 1980, dos trabalhos de Ballion (1982, 1986), as pesquisas sobre o tema se expandiram e se diversificaram nos anos de 1990 e no começo do século xxI.

Parte desse movimento talvez se explique por modificações na própria realidade social. Vários autores chamam a atenção para o fato de que uma série de reformas educacionais, implementadas a partir dos anos de 1980, em diferentes países, ampliou a possibilidade dos pais definirem, mesmo no interior da rede pública, os estabelecimentos escolares que desejam para seus filhos. Como observam Barroso e Viseu (2003), em países como, por exemplo, Inglaterra, Estados Unidos, Austrália, Nova Zelândia, Chile, essas reformas foram influenciadas diretamente pela ideologia liberal que dominou o final do século xx e o início deste século. Orientados por essa perspectiva política e econômica, esses países apostaram, de forma mais ou menos radical, no papel do mercado e da concorrência como instrumentos capazes de ampliar a eficiência do sistema escolar. Assim, os pais foram estimulados a comparar e a escolher a escola pública que consideravam melhor para os seus filhos, servindose para isso, entre outras coisas, de informações padronizadas, geradas pelos órgãos públicos, concernentes ao modo de organização e aos resultados acadêmicos dos diferentes estabelecimentos de ensino. As escolas, por sua vez, foram levadas a competir pelos alunos, a partir de uma política que atrelava os recursos recebidos pela instituição - e, em alguns casos, a própria remuneração dos professores - ao número de matrículas e aos resultados acadêmicos obtidos pelo estabelecimento. 
Ainda segundo Barroso e Viseu (2003), em outros países, como França, Portugal, Alemanha e Noruega, as reformas foram menos radicais, sendo também menos evidente sua vinculação com a ideologia liberal e sua crença no papel do mercado. De qualquer forma, também nesses países, concedeu-se maior autonomia aos estabelecimentos de ensino, visando torná-los mais eficazes e adaptados às demandas existentes em seus contextos locais. No que se refere aos pais, foram implementadas políticas de flexibilização da obrigatoriedade de matricularem os filhos na escola de seu distrito residencial. Na França, por exemplo, além de experiências localizadas de suspensão total dessa obrigatoriedade, criaram-se mecanismos oficiais, mais gerais, por meio dos quais os pais podem questionar a determinação dos órgãos públicos e demandar a matrícula dos filhos em outro estabelecimento de sua preferência.

Qualquer que seja o conjunto de países considerado, é preciso observar ainda que essa ampliação da possibilidade de escolha pelos pais não decorre apenas de uma ação do Estado. Ela é igualmente e inseparavelmente fruto de um desejo crescente de participação dos pais na vida escolar dos filhos, desejo este diretamente associado a transformações na estrutura e nas dinâmicas (demográficas, econômicas, de mentalidade) das famílias. Tais transformações produzem efeitos variados nos modos de criação dos filhos, dentre os quais destacamos, para fins da problemática aqui tratada, a intensificação dos investimentos parentais na escolarização da prole, concebida como a estratégia, por excelência, para garantir um destino (pessoal e social) favorecido para os filhos (Nogueira, 2005).

Enfim, toda essa conjuntura de expansão do exercício de escolha pelos pais contribuiu para uma verdadeira explosão, nas últimas décadas, do interesse pelo tema da escolha do estabelecimento de ensino pelas famílias, sobretudo nos países mais desenvolvidos e que são também os principais centros produtores de conhecimento em Sociologia da Educação. Tal interesse tem levado à realização de uma série de pesquisas, cujos resultados são extremamente significativos. Fundamentalmente, elas evidenciam o caráter social e, portanto, sociologicamente inteligível do ato de escolha da instituição escolar. Há certo consenso, na literatura, de que não se pode reduzir tal ato a uma conduta racional de atores sociais que, servindo-se de critérios universais de avaliação, fariam um cálculo de tipo "custos/benefício" para escolher entre todas as opções objetivamente disponíveis.

Em primeiro lugar, a própria possibilidade de escolher varia de um meio social a outro. $\mathrm{O}$ acesso a escolas particulares e pagas - sobretudo as de maior prestígio - é restrito, obviamente, a apenas uma parcela da população. Mas, mesmo no que se refere à escolha entre estabelecimentos públicos, é preciso lembrar que os custos diretos e indiretos relacionados à escolha (desde o gasto financeiro que pode significar o deslocamento da criança até uma escola mais distante, até o tempo que se precisa investir pesquisando e visitando diferentes escolas) são proporcionalmente 
mais elevados para os pais economicamente menos aquinhoados. Assim, é racionalmente compreensível que a maior parte desses pais simplesmente encaminhe seus filhos para a escola indicada pelo poder público, normalmente situada próximo ao domicílio.

Em segundo lugar, mesmo quando a escolha é possível, as famílias apresentam uma propensão diferenciada a exercê-la. A propensão a escolher ou a importância atribuída a esse ato variam em função do lugar que as estratégias de escolarização ocupam no conjunto das estratégias de reprodução da posição de um grupo familiar, num dado contexto sócio-histórico. De modo geral, na medida em que a escolarização tem um peso maior na determinação da posição social e profissional futura da prole, os pais tendem a atribuir maior importância a cada passo da carreira escolar dos filhos, incluindo aí a escolha da escola a ser por eles frequentada. Por isso, essa tendência é particularmente forte entre as parcelas mais escolarizadas da classe média, cuja posição social atual e o futuro dos filhos dependem basicamente da posse de credenciais escolares. Gewirtz et al. (1995) observam que, para boa parte dessas famílias, a escolha do estabelecimento de ensino ocupa um lugar central na vida familiar por um longo período de tempo.

Em terceiro lugar, as pesquisas mostram que também os critérios de escolha variam de um grupo social a outro (Ballion, 1986; Nogueira, 1998). Os pais menos escolarizados e de nível socioeconômico mais baixo tendem a privilegiar critérios práticos ou funcionais, tais como: proximidade da residência, facilidade de transporte, infraestrutura física, presença de outros filhos na escola. Em contrapartida, as famílias socialmente mais bem posicionadas tenderiam a utilizar critérios internos ao processo educativo, tais como o desempenho do estabelecimento nas grandes avaliações sistêmicas, a filosofia e os métodos pedagógicos adotados, as atividades complementares oferecidas e, de modo geral, o clima do estabelecimento. Essas famílias tenderiam também, mais do que as primeiras, a se preocupar em escolher uma escola que seja adequada às características psicológicas e ao perfil escolar específico de cada filho, antecipando-se assim a possíveis desajustamentos (Gewirtz et al., 1995; Ballion, 1991).

Finalmente, mas não menos importante, as pesquisas evidenciam que o volume e a qualidade da informação a que os pais têm acesso no processo de escolha, bem como sua capacidade de decodificação e de utilização estratégica dessa informação variam enormemente segundo os grupos sociais (Nogueira, 1998; Van Zanten, 2006 e 2009). Os pais com maior capital econômico e, sobretudo, cultural tenderiam, por sua própria trajetória escolar mais longa e pela rede social de que fazem parte, a conhecer melhor o sistema educacional, seu funcionamento e sua estratificação interna. Além disso, teriam maior capacidade de acesso e de interpretação das informações obtidas ao longo do processo de escolha da escola para os filhos. 
A escolha do estabelecimento de ensino pelas famílias revela-se, assim, como um fenômeno por meio do qual se pode observar, de forma bastante clara, o peso das desigualdades sociais na determinação das trajetórias escolares. As famílias que possuem recursos econômicos e culturais mais elevados detêm melhores condições de escolher, são mais propensas a fazê-lo, servem-se de critérios academicamente mais relevantes, obtêm mais informações e são mais aptas a utilizá-las. ${ }^{1}$ Essas famílias tendem, assim, a escolher a melhor escola possível para os filhos, o que constitui uma vantagem adicional para eles, comparativamente aos alunos oriundos de meios socialmente menos aquinhoados.

Mesmo em países como o Brasil, onde não foram implementadas políticas públicas explícitas de estímulo à livre escolha do estabelecimento de ensino, as pesquisas começam a mostrar o papel desempenhado pela escolha da escola na construção ou reprodução das desigualdades escolares. Antes de tudo, é preciso reconhecer que possuímos uma rede privada de ensino apenas parcialmente regulada pelo Estado, sobre a qual as leis de mercado operam segundo a lógica da oferta e, sobretudo, da demanda dos pais-usuários, configurando uma nítida hierarquia de prestígio e de qualidade entre as escolas particulares. Nesse contexto, uma série de pesquisas (Almeida, 2009; Perosa, 2009; Aguiar, 2007; Pinto, 2009) tem revelado como os pais das classes médias e superiores escolhem entre essas escolas de acordo com suas estratégias de reprodução social. As frações mais ricas em capital cultural tendem a privilegiar os estabelecimentos que se destacam pela excelência acadêmica, ao passo que as camadas mais equipadas em capital econômico priorizam o perfil social da clientela (cf., respectivamente, Nogueira, 2000, e Nogueira, 2002). As escolhas parecem ser influenciadas ainda por características secundárias dos pais: natureza da ocupação e tipo de inserção profissional (preferência por escolas que estimulam mais a formação intelectual ou a formação para o empreendedorismo); vinculação religiosa e estilo de vida (preferência por escolas confessionais, laicas ou alternativas); experiência pessoal ou profissional de internacionalização (preferência por escolas internacionais e/ou bilíngues). Qualquer que seja o caso, o que se vê nesses meios sociais é a mobilização dos capitais econômico, cultural e social das famílias, de modo a oferecer aos filhos a escola que mais contribua, a curto, médio e longo prazos, para o projeto de formação concebido de acordo com o ethos familiar e, consequentemente, com as estratégias de reprodução social do grupo.

No que tange à rede pública, trabalhos mais recentes, como os de Costa (2008), Costa e Koslinski (2009) e Alves (2008) têm chamado a atenção para o fato de que a escolha do estabelecimento de ensino também vem se tornando uma questão importante para alguns segmentos bem menos privilegiados da população.

Costa e Koslinski (2009) sustentam que, embora não existam no Brasil regras claras ou políticas públicas deliberadas de incentivo à livre escolha ou à concorrência 
entre estabelecimentos, prevalece, na prática, o que eles denominam um "quasemercado oculto". ${ }^{2}$ Do ponto de vista da oferta, os autores demonstram que existem diferenças significativas de prestígio entre escolas da rede pública municipal do Rio de Janeiro e que, em função de sua posição nesse sistema hierarquizado, os estabelecimentos desenvolvem estratégias oficiosas de captação de "bons alunos" e de evitamento de "maus alunos". Do ponto de vista da demanda, eles mostram como os pais mais bem informados, com níveis mais altos de ambição escolar, com recursos econômicos e culturais relativamente mais elevados, e inseridos numa rede de sociabilidade relativamente privilegiada, estão em condições mais favoráveis para escolher e conseguir o ingresso dos filhos nas escolas reconhecidas como de maior prestígio.

Alves (2008), por sua vez, chama a atenção para o fato de que as famílias que desejam uma escola de melhor qualidade para os filhos, mas que não podem arcar com os custos de escolas particulares de alto prestígio, costumam lançar mão de uma das três oportunidades que lhes são disponíveis no mercado: 1) optam por escolas particulares menos dispendiosas e de menor reputação, cujo perfil socioeconômico da clientela não se distingue significativamente daquele da escola pública; 2) submetem-se a sorteios ou outras formas de seleção adotadas por estabelecimentos de educação básica federais ou vinculados a grandes universidades; 3) buscam vaga naquele grupo mais restrito de escolas públicas consideradas de melhor qualidade.

Em suma, quer se trate de países onde impera um "quase-mercado aberto" ou de países, como o Brasil, onde prevalece um "quase-mercado oculto"; quer se trate das elites ou de grupos menos privilegiados, o fato é que a escolha do estabelecimento de ensino surge como uma dimensão importante do processo de construção das desigualdades de escolarização nas sociedades contemporâneas. Cada grupo social realiza suas escolhas dentro do universo de possibilidades que lhe é próprio, utilizando-se de critérios e servindo-se de recursos culturais e econômicos distintos. Cada um deles tende, portanto, a fazer escolhas que refletem e reproduzem essas mesmas desigualdades.

\section{Pesquisa empírica}

Conforme discutido anteriormente, a literatura vem apontando a relação entre o perfil das famílias e o tipo de escolha que realizam no mercado ou "quase-mercado" escolar, sendo que, no que tange aos setores menos favorecidos da população, os estudos nessa linha são mais incipientes. Neste trabalho, buscamos aprofundar o conhecimento em torno do tema, verificando variações no perfil social, cultural e educativo de um conjunto de 299 famílias de Belo Horizonte, de camadas baixas e 
médio-baixas, que se utilizam de tipos diferentes de estabelecimento de ensino fundamental na escolarização da prole: escolas particulares (de custo e prestígio relativamente menores dentro do universo das escolas privadas de Belo Horizonte); uma escola federal; escolas estaduais e municipais de alto desempenho na Prova Brasil; ${ }^{3}$ outras escolas estaduais e municipais. ${ }^{4}$

A construção de uma amostra concentrada nas classes populares e frações inferiores das camadas médias teve o objetivo de assegurar uma relativa homogeneidade da população estudada, ${ }^{5}$ que possibilitasse observar com maior precisão o efeito, sobre as escolhas escolares, de diferenças secundárias entre as famílias. Assim, com base em Alves (2008), supúnhamos que os três primeiros tipos de escolha (escolas privadas, escola federal e escolas estaduais e municipais de melhor desempenho) seriam feitos tendencialmente por famílias mais mobilizadas, em busca de um ensino de maior qualidade para os filhos.

De acordo com esta hipótese, as famílias cujos filhos frequentam escolas pertencentes às redes particular e federal seriam as mais mobilizadas em relação à escolarização da prole: as primeiras, por se disporem a pagar por uma escola particular, apesar de seu nível socioeconômico relativamente baixo, e as últimas, por buscarem uma escola com diferencial de qualidade, vinculada à universidade, e arcarem com os custos financeiros e/ou de tempo necessários para manter os filhos nessa escola, normalmente afastada do domicílio. Já as famílias cujos filhos estão nas escolas públicas de melhor desempenho na Prova Brasil ocupariam o segundo lugar em termos de mobilização escolar. Supusemos, pelo conhecimento prévio da existência desse tipo de prática, que boa parte delas teria intencionalmente burlado o cadastro escolar ${ }^{6}$ como forma de garantirem uma escola de melhor qualidade para os filhos. Finalmente, de acordo com nossa hipótese, as famílias cujos filhos estão matriculados nas demais escolas públicas seriam as menos mobilizadas, uma vez que, supostamente, teriam obedecido passivamente aos ditames do cadastro escolar.

Os 299 pais ou responsáveis foram interrogados por meio de um questionário bastante abrangente, que incluía desde itens relativos à demografia familiar até questões referentes aos comportamentos e atitudes frente à escolarização da prole, passando por aspectos específicos sobre a escolha da escola para os filhos. Os resultados encontrados, tendo em vista o desenho proposto para a pesquisa, permitem discutir algumas questões cruciais relativas à escolha do estabelecimento de ensino pelas famílias. O controle do nível socioeconômico da amostra possibilita comparar o comportamento de famílias que, em relação a certas variáveis objetivas (escolaridade, ocupação e renda), estão relativamente próximas. Podemos, assim, investigar o peso, sobre o processo de escolha do estabelecimento, de diferenças sociais, culturais e educacionais secundárias, possivelmente existentes entre os grupos familiares. 


\section{Perfis das famílias investigadas e escolha do estabelecimento de ensino}

Ao analisar os dados obtidos, na busca de compor um perfil das famílias cujos filhos estão em cada tipo de escola, constatamos inicialmente que, apesar da relativa homogeneidade em termos de macroclassificação socioeconômica, existem diferenças objetivas significativas entre elas, conforme demonstra a tabela a seguir. ${ }^{7}$

\section{Tabela 1}

Variação de aspectos ligados ao perfil socioeconômico das famílias (em \%)

\begin{tabular}{|c|c|c|c|c|c|}
\hline & \multirow{3}{*}{ Variável } & \multicolumn{4}{|c|}{ Tipos de estabelecimentos de ensino } \\
\hline & & \multirow[b]{2}{*}{ Privados } & \multirow[b]{2}{*}{ Federal } & \multicolumn{2}{|c|}{ Municipais e estaduais } \\
\hline & & & & $\begin{array}{l}\text { Quintil superior } \\
\text { do "Prova Brasil" }\end{array}$ & $\begin{array}{l}\text { Abaixo do quintil } \\
\text { superior do } \\
\text { "Prova Brasil" }\end{array}$ \\
\hline a) & $\begin{array}{l}\text { Mães que concluíram } \\
\text { o ensino médio ou } \\
\text { superior* }\end{array}$ & 51,5 & 64,9 & 36,2 & 18,8 \\
\hline b) & $\begin{array}{l}\text { Pais que concluíram } \\
\text { o ensino médio ou } \\
\text { superior }\end{array}$ & 70,5 & 51,3 & 23,4 & 13,9 \\
\hline c) & $\begin{array}{l}\text { Pais na faixa superior da } \\
\text { amostra quanto ao NSE }\end{array}$ & 71,2 & 54,1 & 33,7 & 12,5 \\
\hline d) & $\begin{array}{l}\text { Pai ou outro homem } \\
\text { responsável mora na } \\
\text { residência }\end{array}$ & 82,4 & 78,5 & 74,5 & 69,3 \\
\hline e) & $\begin{array}{l}\text { Famílias que recebem } \\
\text { algum tipo de bolsa }\end{array}$ & 11,8 & 13,9 & 24,5 & 45,5 \\
\hline f) & $\begin{array}{l}\text { Mais de } 6 \text { pessoas na } \\
\text { casa }\end{array}$ & 5,9 & 5,4 & 13,8 & 25,7 \\
\hline g) & $\begin{array}{l}\text { Crianças que têm } 3 \text { ou } \\
\text { mais irmãos }\end{array}$ & 3,0 & 5,4 & 19,2 & 31,7 \\
\hline h) & $\begin{array}{l}\text { Criança classificada } \\
\text { como preta pelo pai ou } \\
\text { responsável }\end{array}$ & 5,9 & 2,7 & 10,6 & 17,8 \\
\hline
\end{tabular}

Notas: ${ }^{*}$ Em toda a amostra, há treze pais e apenas uma mãe com nível superior de escolaridade. ${ }^{* *} \mathrm{~A}$ faixa superior aqui considerada diz respeito à divisão interna de nossa amostra, não significando, portanto, em termos absolutos, uma posição social elevada.

As linhas de (a) a (d) da tabela apresentam variáveis tradicionalmente associadas a um melhor rendimento escolar, enquanto as linhas (e) a (h) indicam variáveis que representam desvantagens sob o mesmo ponto de vista. Observa-se que, nas 
linhas (a) a (d), quase todas as variáveis têm porcentagens descendentes conforme se passa das escolas privadas para a federal, dessa para as municipais e estaduais de melhor desempenho e, finalmente, para as demais escolas municipais e estaduais; o contrário acontece com as variáveis indicadas nas linhas (e) a (h). Há pequenas oscilações nessa regra apenas entre as escolas privadas e as federais, chamando mais atenção aquela que se refere à escolaridade das mães, bem maior na escola federal - dado bastante significativo, uma vez que, segundo a literatura, a escolaridade da mãe é um dos mais importantes fatores de influência sobre o desempenho escolar dos filhos (Silva \& Hasenbalg, 2000).

Em síntese, esses dados indicam que as famílias das escolas estaduais e municipais "comuns" apresentam um nível socioeconômico mais baixo e características demográficas que a literatura sociológica indica serem menos favoráveis à escolarização dos filhos (Glória, 2007). As famílias das escolas estaduais e municipais de melhor desempenho apresentam situação um pouco mais vantajosa; já aquelas cujos filhos estão na federal e nas escolas particulares apresentam um perfil mais favorável, em relação ao conjunto investigado.

Tais resultados colocam em destaque a complexidade das hierarquias socioeconômicas, as quais se estruturam de forma que camadas sociais aparentemente homogêneas, em uma leitura macroscópica, revelam novas nuances de desigualdades ao serem analisadas mais "de perto". Dessa forma, o fato de as crianças frequentarem escolas diferentes não indicaria, simplesmente, estratégias educativas distintas - incluindo a própria escolha do estabelecimento - dentro de uma população relativamente homogênea. Em que pese nossos esforços de homogeneização da amostra, continuaríamos a ter famílias com perfis socioeconômicos até certo ponto diferenciados, aos quais a escolha da escola parece estar associada.

Cabe destacar que, em termos gerais, essa mesma diferenciação entre os quatro grupos se observou, também, no que se refere à existência, na residência, de bens culturais objetivados (Bourdieu, 1998), tais como livros, jornais, revistas, livros infantis e outros. Tanto em relação a esse aspecto quanto no que tange às práticas culturais das famílias, a tendência predominante foi a formação de dois blocos bem distintos, com situação mais vantajosa para os pais das escolas federais e das particulares (Tabela 2).

Observa-se pela tabela que os pais da escola federal se destacam com relação a diversos aspectos, especialmente quanto à existência de livros infantis na casa, às conversas com os filhos sobre leituras e às visitas a museus e exposições.

Um segundo conjunto de dados merece ser ressaltado, por sua relação direta com a escolha do estabelecimento de ensino. Trata-se do grau de conhecimento do sistema de ensino que os pais detêm e dos projetos de futuro feitos por eles para os 
filhos (Tabela 3), aspectos destacados tanto por Bourdieu (1998), na discussão da relação entre posição social e destino escolar, quanto por autores contemporâneos, ao discutir fatores de influência na escolha do estabelecimento de ensino pelas famílias (Ballion, 1991; Ball \& Vincent, 1998).

\section{Tabela 2}

Variação de aspectos referentes à posse de livros e a práticas culturais das famílias (em \% de respostas)

\begin{tabular}{|c|c|c|c|c|c|}
\hline & \multirow{3}{*}{ Variável } & \multicolumn{4}{|c|}{ Tipos de estabelecimentos de ensino } \\
\hline & & \multirow[b]{2}{*}{ Privados } & \multirow[b]{2}{*}{ Federal } & \multicolumn{2}{|c|}{ Municipais e estaduais } \\
\hline & & & & $\begin{array}{l}\text { Quintil superior } \\
\text { do "Prova Brasil" }\end{array}$ & $\begin{array}{l}\text { Abaixo do quintil } \\
\text { superior do } \\
\text { "Prova Brasil" }\end{array}$ \\
\hline a) & $\begin{array}{l}\text { Não há livros de } \\
\text { literatura na casa }\end{array}$ & 23,5 & 29,7 & 40,4 & 41,6 \\
\hline b) & $\begin{array}{l}\text { Não há livros infantis } \\
\text { na casa }\end{array}$ & 5,9 & 0 & 11,7 & 10,9 \\
\hline c) & $\begin{array}{l}\text { Mãe raramente ou } \\
\text { nunca lê livros }\end{array}$ & 33,8 & 32,4 & 43,6 & 49,5 \\
\hline d) & $\begin{array}{l}\text { Entrevistado nunca ou } \\
\text { quase nunca conversa } \\
\text { com a criança sobre o } \\
\text { que ela leu }\end{array}$ & 26,5 & 18,9 & 43,6 & 37,6 \\
\hline e) & $\begin{array}{l}\text { Entrevistado nunca ou } \\
\text { quase nunca conversa } \\
\text { com a criança sobre } \\
\text { coisas que leu }\end{array}$ & 38,2 & 29,7 & 55,3 & 51,5 \\
\hline f) & $\begin{array}{l}\text { Pais visitam museus } \\
\text { ou exposições com o } \\
\text { filho, duas a três vezes } \\
\text { ao ano }\end{array}$ & 25,0 & 32,4 & 10,6 & 6,9 \\
\hline
\end{tabular}

Com relação a essas variáveis, mais uma vez se observa, em linhas gerais, a formação de dois blocos, entre as famílias das escolas municipais e estaduais (de melhor desempenho e "comuns") e as das escolas privadas e federal.

No caso do projeto de futuro para os filhos, chama a atenção o fato de os pais da escola federal apresentarem um grau de ambição escolar bem mais elevado do que os demais, incluindo aqueles dos estabelecimentos privados. Coerentemente com esse perfil, eles são, também, os que em maior proporção afirmam que a entrada do filho no mundo do trabalho só deve ocorrer após os 21 anos. ${ }^{8}$ 


\section{Tabela 3}

Variação de aspectos referentes aos projetos de futuro para os filhos e ao conhecimento do sistema de ensino pelos pais (em \% de respostas)

\begin{tabular}{|c|c|c|c|c|c|}
\hline & \multirow{3}{*}{ Variável } & \multicolumn{4}{|c|}{ Tipos de estabelecimentos de ensino } \\
\hline & & \multirow[b]{2}{*}{ Privados } & \multirow[b]{2}{*}{ Federal } & \multicolumn{2}{|c|}{ Municipais e estaduais } \\
\hline & & & & $\begin{array}{l}\text { Quintil superior } \\
\text { do "Prova Brasil" }\end{array}$ & $\begin{array}{c}\text { Abaixo do quintil } \\
\text { superior do "Prova } \\
\text { Brasil" }\end{array}$ \\
\hline a) & $\begin{array}{l}\text { Deseja que o filho } \\
\text { estude até a pós- } \\
\text { graduação }\end{array}$ & 17,6 & 32,4 & 11,7 & 7,9 \\
\hline b) & $\begin{array}{l}\text { Considera que o filho } \\
\text { só deve começar a } \\
\text { trabalhar após os } 21 \\
\text { anos }\end{array}$ & 20,6 & 27,0 & 9,6 & 15,8 \\
\hline c) & $\begin{array}{l}\text { Tem conhecimento das } \\
\text { instituições gratuitas } \\
\text { de ensino superior de } \\
\text { Belo Horizonte }\end{array}$ & 82,4 & 83,8 & 44,7 & 37,6 \\
\hline d) & $\begin{array}{l}\text { Define corretamente o } \\
\text { termo "vestibular" }\end{array}$ & 39,7 & 40,5 & 26,6 & 19,8 \\
\hline
\end{tabular}

Quanto ao grau de conhecimento do sistema de ensino por parte dos pais, esses responderam a questões como: se existem universidades gratuitas em Belo Horizonte e quais seriam elas; se sabiam o que é o vestibular, o ENEM e o PRounI. As respostas dadas às questões abertas foram posteriormente categorizadas como certas, parcialmente certas ou erradas. Observou-se que, nesse caso, as diferenças entre o "bloco" das escolas privadas e federal, por um lado, e o das escolas municipais e estaduais, por outro, são bastante significativas, indicando maior conhecimento do sistema de ensino pelos pais do primeiro grupo.

Outro conjunto de variáveis investigadas dizia respeito ao acompanhamento direto da escolaridade dos filhos, incluindo estratégias como auxílio no dever de casa e supervisão dos cadernos (Tabela 4) - as quais, ainda que não possam ser diretamente correlacionadas a um melhor desempenho escolar (Glasman, 2005), certamente são indicativas de mobilização familiar face à escola.

Novamente, o grande destaque parece ser o das famílias da escola federal. Os resultados sugerem que os pais dessa escola, mesmo estando, no que se refere a vários aspectos objetivos, em posição inferior à dos pais das escolas privadas, dedicam-se mais ao acompanhamento da escolarização dos filhos. Observa-se também que a maior parte dos dados tem sentido descendente quanto à frequência 
do acompanhamento, das escolas federais para as particulares, em seguida para as municipais e estaduais de melhor desempenho no "Prova Brasil" e, finalmente, para as demais escolas estaduais e municipais.

\section{Tabela 4}

Variação de aspectos referentes ao acompanhamento direto da escolaridade dos filhos (em \% de respostas)

\begin{tabular}{|c|c|c|c|c|c|}
\hline & \multirow{3}{*}{ Variável } & \multicolumn{4}{|c|}{ Tipos de estabelecimentos de ensino } \\
\hline & & \multirow[b]{2}{*}{ Privados } & \multirow[b]{2}{*}{ Federal } & \multicolumn{2}{|c|}{ Municipais e estaduais } \\
\hline & & & & $\begin{array}{l}\text { Quintil superior } \\
\text { do "Prova Brasil" }\end{array}$ & $\begin{array}{c}\text { Abaixo do quintil } \\
\text { superior do "Prova } \\
\text { Brasil" }\end{array}$ \\
\hline a) & $\begin{array}{l}\text { Gasta mais de } \\
\text { uma hora por dia } \\
\text { ajudando o filho nos } \\
\text { deveres de casa }\end{array}$ & 37,3 & 48,6 & 36,2 & 30 \\
\hline b) & $\begin{array}{l}\text { Raramente ou nunca } \\
\text { olha os cadernos do } \\
\text { filho }\end{array}$ & 8,8 & 2,7 & 10,6 & 9,9 \\
\hline c) & $\begin{array}{l}\text { Olha os deveres do } \\
\text { filho quase todos os } \\
\text { dias }\end{array}$ & 73,5 & 81,1 & 76,6 & 71,3 \\
\hline d) & $\begin{array}{l}\text { Esclarece dúvidas } \\
\text { sobre o dever de casa } \\
\text { quase todos os dias }\end{array}$ & 55,9 & 67,6 & 48,9 & 42,6 \\
\hline
\end{tabular}

Em síntese, os dados apresentados nas tabelas 2 a 4 são representativos de um conjunto de resultados que parecem confirmar a existência de distintos "perfis culturais e educativos" entre os grupos de famílias, os quais podem ser associados ao tipo de escola frequentada pelo filho e, portanto, à escolha da escola. Mas, como se dá tal escolha? Quais os critérios e procedimentos utilizados pelas famílias no ato de escolher?

No que se refere aos critérios, ${ }^{9}$ as diferenças são claras, algumas das quais expressas na Tabela 5. Os pais das escolas estaduais e municipais comuns são os que mais apontam o horário das aulas e a localização - critérios funcionais, que não se vinculam diretamente ao processo de ensino e aprendizagem. Eles são também os que mais apontam a infraestrutura, a disciplina e a formação moral como o mais importante numa boa escola. Os pais das escolas estaduais e municipais de melhor desempenho atribuem uma importância bem maior que os do primeiro grupo aos métodos e à qualidade de ensino, bem como à recomendação dos amigos. Nesse 
ponto, eles se aproximam, na verdade, dos pais da federal e das particulares, que são os que mais valorizam esses três critérios. Os pais das particulares, no entanto, também levam em consideração, além do valor da mensalidade, a localização e a formação religiosa. ${ }^{10}$

Tabela 5

Variação de aspectos ligados aos critérios de escolha da escola pelas famílias (em \% de respostas)

\begin{tabular}{|c|c|c|c|c|c|}
\hline & \multirow{3}{*}{ Variável } & \multicolumn{4}{|c|}{ Tipos de estabelecimentos de ensino } \\
\hline & & \multirow[b]{2}{*}{ Privados } & \multirow[b]{2}{*}{ Federal } & \multicolumn{2}{|c|}{ Municipais e estaduais } \\
\hline & & & & $\begin{array}{c}\text { Quintil } \\
\text { superior do } \\
\text { "Prova Brasil" }\end{array}$ & $\begin{array}{c}\text { Abaixo } \\
\text { do quintil } \\
\text { superior no } \\
\text { "Prova Brasil" }\end{array}$ \\
\hline \multirow{6}{*}{ 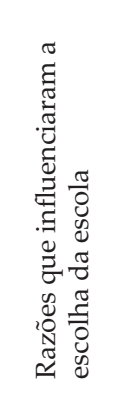 } & -Horário das aulas & 9,5 & 2,8 & 8 & 23,9 \\
\hline & $\begin{array}{l}\text {-Valor da } \\
\text { mensalidade }\end{array}$ & 33,0 & 8,3 & 0 & 0 \\
\hline & -Ser religiosa & 30,2 & 0 & 0 & 0 \\
\hline & -Qualidade de ensino & 91,7 & 93,7 & 88 & 71,7 \\
\hline & $\begin{array}{l}\text {-Recomendação de } \\
\text { amigos }\end{array}$ & 60,3 & 52,8 & 46,0 & 32,6 \\
\hline & -Localização & 77,8 & 30,6 & 58,0 & 67,4 \\
\hline \multirow{2}{*}{ 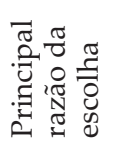 } & $\begin{array}{l}\text {-Qualidade do } \\
\text { ensino }\end{array}$ & 57,1 & 86,1 & 78,0 & 53,2 \\
\hline & -Localização & 19,0 & 5,6 & 14,0 & 42,6 \\
\hline \multirow{3}{*}{ 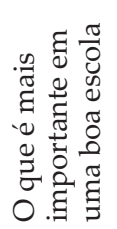 } & -Infraestrutura & 0 & 2,8 & 4,3 & 11,9 \\
\hline & -Métodos de ensino & 85,3 & 80,6 & 71,3 & 59,4 \\
\hline & $\begin{array}{l}\text {-Disciplina e } \\
\text { formação moral }\end{array}$ & 14,7 & 16,7 & 24,5 & 28,7 \\
\hline
\end{tabular}

Em relação a esses dados, mais uma vez se destacam os pais da escola federal, pela forte valorização de critérios acadêmicos, como qualidade e métodos de ensino adotados pela escola. 


\section{Considerações finais}

Conforme discutido no primeiro tópico deste texto, a temática da escolha do estabelecimento de ensino pelas famílias vem ganhando força no âmbito da Sociologia da Educação, mobilizando estudiosos interessados em aprofundar o conhecimento das relações entre família e escola e, em termos mais gerais, entre educação e sociedade. No Brasil, essa temática, embora ainda incipiente, já conta com vários estudos, inicialmente voltados para a escolha da escola pelos setores mais favorecidos da população (Almeida, 2009; Aguiar, 2007; Perosa, 2009) e, mais recentemente, abordando também as disputas, entre as camadas menos favorecidas, por estabelecimentos que, dentro do campo de possibilidades das famílias desses meios, representem diferenciais de qualidade (Costa \& Koslinski, 2009; Alves, 2008).

O estudo apresentado neste texto vem se somar aos desse último grupo. Ao investigar um conjunto de famílias relativamente homogêneo do ponto de vista macroestrutural, que têm filhos matriculados em diferentes tipos de estabelecimentos de ensino, o trabalho buscou lançar luz sobre diferenças secundárias entre essas famílias que pudessem explicar as escolhas por elas realizadas no que tange à escola para os filhos. Analisou, para isso, aspectos referentes ao perfil social, cultural e educativo das famílias e também aos critérios empregados na ação de escolha.

A conclusão mais geral dessa análise é a constatação de variações significativas nesse perfil, em relação a todos os aspectos considerados, conforme o tipo de escola: privada, federal, estadual e municipal de melhor desempenho no "Prova Brasil" e demais escolas estaduais e municipais. De forma geral, as famílias desses quatro tipos de escolas, consideradas nessa ordem, ocupam posições descendentes no que tange a condições favorecedoras do sucesso escolar ou indicadoras de maior mobilização face à escolarização dos filhos. Há, entretanto, diferenciações, sendo que a mais fortemente observada foi a tendência de formação de dois agrupamentos com resultados contrastantes: o primeiro constituído pelas escolas federal e privadas e o outro, pelas estaduais e municipais. Outro resultado recorrente foi o destaque da escola federal sobre as demais, inclusive as escolas privadas, no que tange às condições já mencionadas. ${ }^{11}$

Esses resultados, antes de tudo, confirmam as pesquisas até então existentes, tanto internacionais quanto nacionais - já sintetizadas neste artigo -, que apontam a relação entre escolha do estabelecimento de ensino e perfis familiares, evidenciando o caráter social dessa escolha. Parece haver uma contribuição específica deste estudo ao identificar diferentes perfis de famílias no interior de um universo que, em outro tipo de abordagem, poderia ser homogeneizado, sob macroclassificações socioeconômicas, como pertencente às classes médio-baixas e populares. 
Ao focalizar esse universo, o estudo corrobora a ideia de que também entre os setores menos favorecidos da população ocorrem processos ativos e diferenciados de escolha do estabelecimento de ensino pelas famílias, os quais devem merecer a atenção do sociólogo da educação. Ao mesmo tempo, os resultados obtidos levam a uma discussão sobre os fundamentos dessa diferenciação.

Por um lado, a hipótese inicial de que as diferentes escolhas estariam associadas a distintos graus de mobilização familiar quanto à escolaridade dos filhos encontra respaldo nos dados levantados, os quais indicam variações, entre os quatro grupos de famílias, quanto a aspectos como o acompanhamento da escolaridade dos filhos, as práticas culturais, os projetos de escolarização a médio ou longo prazos, os critérios de escolha dos estabelecimentos de ensino. Por outro lado, os resultados indicam, ainda, que essas variações não podem ser consideradas de modo isolado, como se fossem autônomas em relação às condições objetivas das famílias, pois também estão associadas a variações nessas mesmas condições, configurando, em uma análise mais nuançada, nítidas "subestratificações" na amostra. Recoloca-se assim, de certa forma, uma discussão antiga e crucial na Sociologia da Educação: a do grau de autonomia das práticas dos atores e das dinâmicas dos grupos sociais em relação à posição objetiva que ocupam no espaço social.

Como aponta Costa (2008), o que fica claro é um quadro complexo de hierarquias e diferenças socioeconômicas, culturais e educacionais profundamente matizadas e entrelaçadas, diante do qual modelos interpretativos dicotômicos (ricos $\mathrm{x}$ pobres, público $\mathrm{x}$ privado) tornam-se necessariamente insuficientes. Nesse sentido, os dados obtidos nesta pesquisa corroboram a ideia de um "quase-mercado" educativo, no qual se articulam a disponibilidade de diferentes ofertas escolares e a existência de distintos perfis familiares, com demandas diversas do ponto de vista educacional. Investigar a ecologia desse "quase-mercado" (Yair, 1996; Costa \& Koslinski, 2009) constitui, sem dúvida, uma condição importante para se compreender as desigualdades contemporâneas de escolarização.

\section{Notas}

1. Essas conclusões são utilizadas pelos críticos das políticas de livre escolha para argumentar que tais políticas tendem a acentuar as desigualdades no interior dos sistemas públicos de ensino. Para uma discussão sobre os efeitos mais ou menos democratizantes das políticas de livre escolha, ver, entre outros, Ball (1995) e Maroy (2008).

2. A expressão "quase-mercado" tem sido utilizada, pela literatura, para ressaltar as especificidades do mercado escolar (sobretudo no segmento público), o qual combina financiamento público e regulação estatal do ensino com alguma possibilidade de escolha por parte dos pais e de concorrência entre as escolas (Felipe, 2009; Van Zanten, 2005). O termo "quase-mercado oculto" busca indicar a existência, no caso brasileiro, de um forte quase-mercado educacional, porém operando por meio de "mecanismos pouco visíveis ou mesmo deliberadamente ocultados" (Costa \& Koslinski, 2009), em comparação com os quase-mercados regulamentados. 
3. Escolas posicionadas no quintil superior na avaliação da "Prova Brasil" - Língua Portuguesa, 2005.

4. Os dados empíricos foram produzidos no quadro de uma pesquisa mais ampla sobre a influência da família no desempenho de alunos dos anos iniciais do ensino fundamental, pesquisa esta articulada ao "Projeto Geres - Estudo Longitudinal da Geração Escolar 2005". O Geres é uma pesquisa de âmbito nacional que acompanhou, entre os anos de 2005 e 2009, a proficiência escolar de cerca de 21.000 alunos do ensino fundamental, matriculados em 303 escolas públicas e particulares de cinco cidades brasileiras (Belo Horizonte, Rio de Janeiro, Campinas, Salvador e Campo Grande), com o objetivo de identificar as condições e práticas escolares que maximizam a aprendizagem. Já a pesquisa que serve de base a este trabalho, financiada pelo INEP/MEC, teve como principal propósito analisar o impacto dos fatores extraescolares, sobretudo familiares, considerando, para isso, uma subamostra de 299 alunos do GEREs em Belo Horizonte e interrogando seus pais ou responsáveis.

5. No momento de seleção da amostra, já dispúnhamos de uma medida de NSE - nível socioeconômico - construída pelo Projeto GEREs, a qual agrupava variáveis relacionadas à renda, ocupação e escolaridade dos pais. Considerando esses dados para o conjunto dos alunos GEREs em Belo Horizonte, excluiu-se desse universo o quintil superior e selecionou-se a amostra entre os alunos restantes - assegurando, assim, maior concentração nas camadas populares e nas frações inferiores das camadas médias.

6. O Cadastro Escolar por local de moradia é o processo oficial de alocação de vagas nas redes estadual de Minas Gerais e municipal de Belo Horizonte. Neste momento, estamos desenvolvendo um procedimento de georreferenciamento das residências dos alunos e de suas escolas, que tem por objetivo estabelecer a distância entre ambas, a fim de averiguar a hipótese de burla ao cadastro escolar por parte dos pais de alunos das escolas estaduais e municipais de melhor desempenho no Prova Brasil. Os dados iniciais apontam para a confirmação dessa hipótese.

7. Tendo em vista a grande quantidade de dados levantados pela pesquisa e os limites de espaço deste trabalho, selecionamos apenas alguns resultados mais significativos.

8. Surpreende, em relação a este último ponto, o percentual baixo daqueles que apontam idade superior aos 21 anos entre os pais das escolas estaduais e municipais de melhor desempenho.

9. As ações empreendidas pelos pais no processo de escolha também foram investigadas por meio do questionário, mas não serão aqui detalhadas por questões de espaço.

10. Considerando que se trata de pais de camadas baixas ou médio-baixas, pode-se supor que a escolha da escola particular, em si, já represente a busca de maior qualidade acadêmica e que, dentro do universo de escolas privadas a que têm acesso, esses pais escolhem levando em conta outros critérios como localização, valor da mensalidade, formação religiosa.

11. Especificidades como essa apresentada pelas famílias da escola federal, bem como alguns aspectos ainda não esclarecidos na pesquisa, serão objeto de estudo qualitativo já planejado pelo grupo.

\section{Referências}

AGUIAR, A. O recurso às escolas internacionais como estratégia educativa de famílias socialmente favorecidas. 2007. 242p. Tese (Doutorado em Educação) - Universidade Federal de Minas Gerais, Belo Horizonte.

ALMEIDA, A.M.F. As escolas dos dirigentes paulistas. Belo Horizonte: Argvmentvm, 2009.

ALVES, F.C.M. Escolhas familiares no contexto da estratificação educacional e residencial da cidade do Rio de Janeiro. Seminário GERES, Belo Horizonte, abr. 2008. 
BALL, S. Mercados educacionais, escolha e classe social. In: Gentili, P. (Org.). Pedagogia da exclusão. Petrópolis: Vozes, 1995. p. 196-227.

BALL, S.; VINCENT, C. "I heard it on the grapevine": "hot" knowledge and school choice. British Journal of Sociology of Education, Oxfordshire, v. 19, n. 3, p. 377-400, 1998.

BALLION, R. Les consommateurs d'école. Paris: Stock, 1982.

BALLION, R. Les familles et le choix du collège. L'Orientation Scolaire et Professionnelle, Paris, v. 15, n. 3, p. 183-202, 1986.

BALLION, R. La bonne école. Paris: Hatier, 1991.

BARROSO, J.; VISEU, S. A emergência de um mercado educativo no planejamento da rede escolar: de uma regulação pela oferta a uma regulação pela procura. Educação E Sociedade, Campinas, v. 24, n. 84, p. 897-921, 2003.

BOURDIEU, P. Escritos de educação. Petrópolis: Vozes, 1998.

COSTA, M. Prestígio e hierarquia escolar: estudo de caso sobre diferenças entre escolas em uma rede municipal. Revista Brasileira de Educação, Rio de Janeiro, n. 39, p. 455-469, set./dez. 2008.

COSTA, M.; KOSLINSKI, M. C. Escolha, estratégia e competição por escolas públicas: pensando a ecologia do quase-mercado escolar. In: ENCONTRO ANUAL DA ANPOCS, 33., 2009, Caxambu. 2009. Disponível em: <www.anpocs.org.br>

FELIPE, L. H. L. "Mercado escolar": contornos de um debate no campo educacional. In: ENCONTRO ANUAL DA ANPOCS, 33., 2009, Caxambu. 2009. Disponível em: $<$ www.anpocs.org.br>.

GEWIRTZ, S.; BALL, S.; BOWE, R. Markets, choice and equity in education. Buckingham: Open University, 1995.

GLASMAN, D. Le travail des élèves: pour l'école en dehors de l'école. Chambery: Université de Savoie, 2005.

GLÓRIA, D.M.A. Uma análise de fatores sociodemográficos e sua relação com a escolarização dos filhos em camadas médias. 2007. 288f. Tese (Doutorado em Educação) - Programa de Pós-Graduação em Educação, Universidade Federal de Minas Gerais, Belo Horizonte.

MAROY, C. Por qué y cómo regular el mercado educativo? Profesorado: Revista de Currículum y Formación del Professorado, Granada, v. 12, n. 2, p. 1-11, 2008. Disponível em: $<$ http//www.ugr.es/ recfpro/rev122ART1.pdf $>$. 
NOGUEIRA, M.A. A escolha do estabelecimento de ensino pelas famílias: a ação discreta da riqueza cultural. Revista Brasileira de Educação, Rio de Janeiro, n. 7, p. 4256, jan./abr. 1998.

NOGUEIRA, M.A. A construção da excelência escolar: um estudo feito com estudantes universitários provenientes das camadas médias intelectualizadas. In: Nogueira, M.A.; Romanelli, G.; Zago, N. (Org.). Família e escola: trajetórias de escolarização em camadas médias e populares. Petrópolis: Vozes, 2000. p. 125-154.

NOGUEIRA, M.A. Estratégias de escolarização em famílias de empresários. In: ALmeidA, A.; Nogueira, M.A. (Org.). A escolarização das elites: um panorama internacional da pesquisa. Petrópolis: Vozes, 2002. p. 49-65.

NOGUEIRA, M. A. A relação família escola na contemporaneidade: fenômeno social/interrogações sociológicas. Análise Social, Lisboa, v. 40, n. 176, p. 563-578, 2005.

PEROSA, G.S. Escola e destinos femininos: São Paulo, 1950/1960. Belo Horizonte: Argvmentvm, 2009.

PINTO, J.S.S. A escolha de Escolas Waldorf por famílias de camadas médias. 2009. $126 f$. Dissertação (Mestrado em Educação) - Programa de Pós-Graduação em Educação, Universidade Federal de Minas Gerais, Belo Horizonte.

SILVA, N. V.; HASENBALG, C. Tendências da desigualdade educacional no Brasil. Dados, Rio de Janeiro, v. 43, n. 3, p. 423-445, 2000.

VAN ZANTEN, A. Efeitos da concorrência sobre a atividade dos estabelecimentos escolares. Cadernos de Pesquisa, São Paulo, v. 35, n. 126, p. 565-593, 2005.

VAN ZANTEN, A. Reflexividad y elección de la escuela por los padres de la clase media en Francia. Revista de Antropologia Social, Madrid, n. 16, p. 245-278, 2006.

VAN ZANTEN, A. Choisir son école. Paris: PUF, 2009.

YAIR, G. School organization and market ecology: a realist sociological look at the infrastructure of school choice. British Journal of Sociology of Education, Oxfordshire, v. 7, n. 4, p. 453-471, 1996.

Recebido em 14 de maio de 2010.

Aprovado em 18 de fevereiro de 2011. 